\title{
An audit of elective outpatient magnetic resonance imaging in a tertiary South African public-sector hospital
}

\author{
Authors: \\ Francois van Schouwenburg \\ Christelle Ackermann ${ }^{1}$ \\ Richard Pitcher ${ }^{1}$ \\ Affiliations: \\ ${ }^{1}$ Division of Radiodiagnosis, \\ Department of Medical \\ Imaging and Clinical \\ Oncology, Faculty of \\ Medicine and Health \\ Sciences, Tygerberg Hospital \\ and Stellenbosch University, \\ South Africa
}

\section{Correspondence to:}

Francois van Schouwenburg

Email:

vanschou@gmail.com

\section{Postal address:}

20 Boschendal Terrace, Van

Riebeeckshof, Bellville 7530,

South Africa

\section{Dates:}

Received: 14 July 2014

Accepted: 27 Oct. 2014

Published: 09 Dec. 2014

How to cite this article: Van Schouwenburg, F., Ackermann, Pitcher, R. An audit of elective outpatient magnetic resonance imaging in a tertiary South African public-sector hospital. S Afr J Rad. 2014;18(1); Art. \#689, 5 pages. http://dx.doi/ org/10.4102/sajr.v18i1.689

\section{Copyright:}

(C) 2014. The Authors. Licensee: AOSIS

OpenJournals. This work is licensed under the Creative Commons Attribution License.
Background: Increasing demand for magnetic resonance imaging (MRI) has resulted in longer waiting times for elective MRI, particularly in resource-limited healthcare environments. However, inappropriate imaging requests may also contribute to prolonged MRI waiting times. At the time of the present study, the waiting time for elective MRI studies at Tygerberg Hospital (TBH), a tertiary-level public-sector healthcare facility in Cape Town (South Africa), was 24 weeks.

Objectives: To document the nature and clinical appropriateness of scheduled TBH outpatient MRI examinations.

Method: A retrospective analysis of the referral forms of all elective outpatient MRI examinations scheduled at TBH from 01 June to 30 November 2011 was conducted. Patient age, gender, clinical details, provisional diagnosis, examination requested and referring clinician were recorded on a customised data sheet. Two radiologists independently evaluated the appropriateness of each request by comparing the clinical details and the provisional diagnosis provided with the 2012 American College of Radiology (ACR) guidelines for the appropriate use of MRI.

Results: Four hundred and sixty-six patients (median age 42 years; interquartile range 19-55) who had 561 examinations were scheduled in the review period; $70(15 \%)$ were children less than 6 years old. Neurosurgery $(n=164 ; 35 \%)$, orthopaedic $(n=144 ; 31 \%)$, neurology $(n=53 ; 11 \%)$ and paediatric $(n=27 ; 6 \%)$ outpatients accounted for the majority $(81 \%)$ of referrals; $464(99.6 \%)$ were from specialist clinics. MRIs of the spine $(n=314 ; 56 \%)$, brain $(n=152 ; 27 \%)$ and musculoskeletal system $(n=70,13 \%)$ accounted for more than $95 \%$ of the investigations. In 455 cases $(98 \%)$, the referral was congruent with published ACR guidelines for appropriate MRI utilisation.

Conclusion: Scheduled outpatient MRI examinations at TBH reflect optimal clinical use of a limited resource. MRI utilisation is largely confined to traditional neuro-imaging. Any initiative to decrease the elective MRI waiting time should focus on service expansion.

\section{Introduction}

As a diagnostic modality, magnetic resonance imaging (MRI) affords unsurpassed tissue contrast without exposing patients to the harmful effects of ionising radiation. ${ }^{1}$ In the 35 years since its first clinical use, MRI has established a pivotal role in central nervous system (CNS) imaging. ${ }^{2,3,4}$ Furthermore, as a result of ongoing technical advances that have consistently increased spatial resolution, decreased scan times and contributed to the development of new imaging sequences, MRI currently plays a burgeoning role in musculoskeletal, cardiac, hepatobiliary, gastrointestinal, urogenital, gynaecological, fetal, vascular and paediatric imaging. $5,6,7,8,9,10$

The ever-increasing clinical applications of MRI have resulted in a proliferation of scanners in well-resourced countries. Japan and North American and Western European countries now have between 6 and 41 MRI scanners per million population. Given the high capital and operating costs of MRI systems, this relative plethora of scanners has raised concerns of overuse and fears

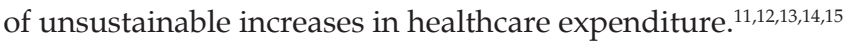

Whilst the South African private healthcare sector has adequate MRI resources, those in the public sector are limited. In the public healthcare sector of Western Cape Province, where this study was conducted, only three 1.5-Tesla MRI scanners serve approximately 4.4 million people, equating to 0.7 scanners per million population. ${ }^{16}$

One of the Western Cape's public-sector MRI scanners is installed at Tygerberg Hospital (TBH), a tertiary-level teaching facility offering a broad range of medical, surgical, paediatric, obstetric, 
oncological and psychiatric specialist and subspecialist services. At the time of this study, TBH possessed a 1.5-T Siemens Magnetom Symphony MRI scanner, commissioned in 2002. Elective outpatient MRI scans were scheduled during normal working hours (weekdays 08h00-16h00). The waiting time for elective MRI scans was 24 weeks.

The present study was prompted by an initiative of the Department of Health of the Provincial Government of Western Cape Province to increase access to specialised radiological services, and particularly MRI, in the knowledge that early access to appropriate MRI improves patient outcomes. Furthermore, MRI waiting time represents a key performance indicator for modern radiology departments and healthcare systems. . $^{17,18,19}$

Long MRI waiting times are not the exclusive domain of resource-limited healthcare environments, and have been documented in well-resourced countries, ${ }^{18,19,20,21}$ being attributed to ever-increasing clinical indications for MR examinations, a growing clinician dependence on diagnostic imaging, and inappropriate imaging requests. ${ }^{18}$ The nature of scans performed has also been shown to affect patient throughput and thus indirectly influence access. Prolonged scanning time is associated with the body region scanned, conducting several examinations on a single patient, use of oral and intravenous contrast agents, and the scanning of young children. ${ }^{20}$

Waiting times may be shortened by matching supply with demand. Reduced demand could be achieved by eliminating inappropriate investigations, whilst an increase in supply requires service expansion. ${ }^{20}$ The present study was undertaken from the standpoint that inappropriate examinations should be eliminated prior to considering service changes. At the time of the study, all TBH MRI requests were screened and approved by a consultant radiologist. Although departmental protocols were available for the validation of emergency MR scans, no formal guidelines governed the approval of elective scans; this was seen as the prerogative of the duty consultant, based on the clinical merit of each case. No formal quality assurance procedures were in place to assess the appropriateness of elective scan validation.

Coinciding with the commencement of the study, guidelines for the appropriate clinical use of MRI were published by the American College of Radiologists (ACR). ${ }^{22}$ Studies of MRI utilisation in well-resourced countries have shown that referral patterns are determined by ease of access to the modality. ${ }^{23}$ To the best of our knowledge, there is no comparable data from resourcelimited healthcare environments, where a different disease burden and more stringent resource constraints may affect MRI utilisation. Knowledge of the utilisation of capitalintensive healthcare resources is important at provincial and national government level to facilitate planning for optimal public-sector resource allocation, particularly in resource-restricted environments. It was hypothesised that inadequate vetting of clinical referrals contributed substantially to the long waiting times for elective $\mathrm{TBH}$ MRI examinations.

\section{Aim}

To document the nature and clinical appropriateness of scheduled TBH outpatient MRI examinations.

\section{Methods}

A retrospective analysis of the referral forms of all elective outpatient MRI examinations scheduled at TBH from 01 June - 30 November 2011 was conducted. Patient age, gender, clinical details, provisional diagnosis, the examination requested and referring clinician were recorded on a customised data sheet. Two radiologists independently evaluated the appropriateness of each MR request by comparing the clinical details and the provisional diagnosis provided on the request form, with the 2012 ACR guidelines for the appropriate use of MRI.22 Where radiologists differed in their individual assessment of the appropriateness of an imaging request, consensus was reached after discussion.

\section{Ethical considerations}

The study was approved by the Health Research Ethics Committee of the Faculty of Medicine and Health Sciences at Stellenbosch University and by TBH Management.

\section{Results \\ Patient load}

Four hundred and sixty-six outpatients (female $=267 ; 57 \%$ ) with a median age of 42 years (interquartile range 19-55), had 561 elective examinations scheduled in the review period. Multiple examinations were requested for 72 (16\%) patients; $70(15 \%)$ patients were below the age of six years and required sedation or general anaesthesia for a technically optimal study.

\section{Referring departments}

The neurosurgery $(n=164 ; 35 \%)$, orthopaedic $(n=144 ; 31 \%)$, neurology $(n=53 ; 11 \%)$ and paediatric $(n=57 ; 6 \%)$ outpatient clinics accounted for the majority $(81 \%)$ of referrals. With the exception of two cases from general outpatients, referrals ( $n=464 ; 99.6 \%)$ were from specialist or subspecialist clinics (Table 1).

\section{Scheduled examinations}

Examinations of the spine $(n=314 ; 56 \%)$, brain $(n=152 ; 27 \%)$ and musculoskeletal system $(n=70,13 \%)$ accounted for more than $95 \%$ of investigations (Table 2).

\section{Clinical indications for referrals}

\section{Magnetic resonance imaging spine}

More than $90 \%(n=284)$ of examinations were referred from the neurosurgery, $(153 / 314 ; 49 \%)$, orthopaedic $(108 / 314 ; 34 \%)$ 
and neurology $(23 / 314 ; 7 \%)$ outpatient clinics. More than half were for degenerative disease of the spine $(161 / 314 ; 51 \%)$ (Table 2).

\section{Magnetic resonance imaging brain}

Referrals from neurosurgery $(48 / 152 ; 32 \%)$, neurology $(41 / 152$; $27 \%)$, paediatrics $(28 / 152 ; 18 \%)$ and endocrinology $(18 / 152$; $12 \%)$ predominated. Definitive evaluation of an intracranial mass was the most common indication (61/152; 40\%), whilst familial syndromes (22/152; 15\%) and perinatal insults (20/152; $13 \%$ ) together accounted for more than a quarter of referrals.

\section{Musculoskeletal magnetic resonance imaging}

The majority of referrals were from orthopaedic outpatients ( $n=54 / 65 ; 83 \%)$ and indications included follow-up for joint trauma, congenital abnormalities and soft-tissue tumours (Table 2).
TABLE 1: Referrals by outpatient department.

\begin{tabular}{ll}
\hline Department & $\boldsymbol{n ( \% )}$ \\
\hline Neurosurgery & $164(35.1)$ \\
Orthopaedics & $144(30.9)$ \\
Neurology & $53(11.4)$ \\
Paediatrics & $27(5.8)$ \\
Endocrinology & $14(3.0)$ \\
Ear, nose and throat & $12(2.6)$ \\
General surgery & $9(1.9)$ \\
General medicine & $6(1.3)$ \\
Rheumatology & $6(1.3)$ \\
Urology & $4(0.9)$ \\
Psychiatry & $3(0.6)$ \\
Ophthalmology & $3(0.6)$ \\
Oncology & $2(0.4)$ \\
General outpatients & $2(0.4)$ \\
Other & $17(3.6)$ \\
\hline Total & 466 \\
\hline
\end{tabular}

TABLE 2: Examinations and clinical indications by body part.

\begin{tabular}{|c|c|c|c|c|c|}
\hline Clinician & $n(\%)$ & Examination & $n(\%)$ & Clinical Indication & $n(\%)$ \\
\hline \multicolumn{6}{|l|}{ Spine $(n=314 ; 56 \%)$} \\
\hline Neurosurgery & $153(49)$ & Craniocervical junction & $4(1)$ & Degenerative disease & $161(51)$ \\
\hline Orthopaedics & $108(34)$ & Cervical spine & $77(25)$ & Congenital anomaly & $45(14)$ \\
\hline Neurology & $23(7)$ & Thoracic spine & $63(20)$ & Myelopathy & $31(10)$ \\
\hline Oncology & $9(3)$ & Lumbar spine & $170(54)$ & Paraspinal mass & $25(8)$ \\
\hline Paediatrics & $8(3)$ & - & - & Metastatic disease & $13(4)$ \\
\hline Paediatric surgery & $6(2)$ & - & - & Neurological deficit & $12(4)$ \\
\hline Endocrinology & $2(1)$ & - & - & Back pain & $6(2)$ \\
\hline Cardiothoracic surgery & $1(0)$ & - & - & Inadequate history & $6(2)$ \\
\hline Rheumatology & $1(0)$ & - & - & Post surgery & $5(2)$ \\
\hline Urology & $1(0)$ & - & - & Kyphosis & $3(1)$ \\
\hline \multicolumn{6}{|l|}{ Brain $(n=152 ; 27 \%)$} \\
\hline Neurosurgery & $48(32)$ & Standard brain & $140(92)$ & Intracranial mass & $61(40)$ \\
\hline Neurology & $41(27)$ & Pituitary fossa & $9(6)$ & Familial syndromes & $22(15)$ \\
\hline Endocrinology & $18(12)$ & Cerebellum & $1(1)$ & Endocrine workup & $16(11)$ \\
\hline General medicine & $5(3)$ & Brainstem & $1(1)$ & Infection & $11(7)$ \\
\hline Oncology & $3(2)$ & - & - & Seizure disorders & $10(7)$ \\
\hline Psychiatry & $3(2)$ & - & - & Focal neurology & $6(4)$ \\
\hline Genetics & $1(1)$ & - & - & Inadequate history & $4(3)$ \\
\hline Infectious diseases & $1(1)$ & - & - & Psychiatric disorder & $2(1)$ \\
\hline Ophthalmology & $1(1)$ & - & - & - & - \\
\hline Nephrology & $1(1)$ & - & - & - & - \\
\hline Paediatric surgery & $1(1)$ & - & - & - & - \\
\hline General outpatients & $1(1)$ & - & - & - & - \\
\hline \multicolumn{6}{|c|}{ Musculoskeletal $(n=70 ; 13 \%)$} \\
\hline Orthopaedics & $62(89)$ & Knee & $24(34)$ & Post trauma & $26(37)$ \\
\hline Rheumatology & $5(7)$ & Hip & $13(19)$ & Tumour & $12(17)$ \\
\hline \multirow[t]{4}{*}{ Surgery } & $3(4)$ & Ankle & $2(3)$ & Avascular necrosis & $10(14)$ \\
\hline & & Foot & $13(19)$ & Congenital anomaly & $10(14)$ \\
\hline & & Limb & $7(10)$ & Chronic infection & $2(3)$ \\
\hline & & Hand & $3(4)$ & Inadequate history & $1(1)$ \\
\hline \multicolumn{6}{|l|}{ Other $(n=24,4 \%)$} \\
\hline Ear, nose and throat & $12(50)$ & Internal auditory meati & $12(50)$ & Tinnitus, hearing loss & $12(50)$ \\
\hline Ophthalmology & $3(13)$ & Orbits & $3(13)$ & MS, thyroid acropachy & $3(13)$ \\
\hline Oncology & $2(8)$ & Rectum & $2(8)$ & Rectal carcinoma & $2(8)$ \\
\hline Urology & $2(8)$ & MRU & $2(8)$ & Congenital renal anomaly & $2(8)$ \\
\hline Gastroenterology & $1(4)$ & MRCP & $1(4)$ & Idiopathic cholangiopathy & $1(4)$ \\
\hline Paediatric surgery & $1(4)$ & Abdomen & $1(4)$ & Undescended testis & $1(4)$ \\
\hline Paediatric surgery & $1(4)$ & Colostogram & $1(4)$ & Anorectal malformation & $1(4)$ \\
\hline Gynaecology & $1(4)$ & Pelvis & $1(4)$ & Endometriosis & $1(4)$ \\
\hline Surgery & $1(4)$ & Neck & $1(4)$ & Tumour & $1(4)$ \\
\hline
\end{tabular}

$\mathrm{MRU}$, magnetic resonance urography; MRCP, magnetic resonance cholangiopancreatography; MS, multiple sclerosis. 


\section{Appropriateness of scheduled examinations}

In 11 cases $(n=11 / 466 ; 2.4 \%)$, the clinical details provided were considered insufficient to justify approval of the MRI request. In all other cases $(n=455 ; 97.6 \%)$, the clinical indication was congruent with published ACR guidelines for appropriate use of the modality. ${ }^{22}$

\section{Discussion}

To our knowledge, the present study is the first of its kind in a tertiary hospital in a resource-restricted environment, and provides important insights into the utilisation of MRI in such a setting.

We have shown only limited use of MRI by clinicians other than neurosurgeons, orthopaedic surgeons and neurologists, suggesting that, in a resource-limited environment, utilisation is confined to the more established clinical indications, and the role of MRI in areas such as oncology, cardiology, urology, hepatobiliary, gastro-enterology, female imaging and fetal medicine is constrained.

The study has also shown that the vast majority $(97.6 \%)$ of scheduled TBH elective outpatient MRI examinations had sound clinical indications, representing optimal use of a limited resource. A number of recent studies have outlined management options when attempting to align imaging capacity with demand. ${ }^{19,21}$

Given the appropriateness of TBH clinical referrals and the knowledge that MRI utilisation at TBH was confined to a relatively narrow spectrum of 'classical' brain, spine and musculoskeletal studies, it was felt that the only way to address the waiting list was to extend the hours of operation. Of note is that no attempt was made to modify institutional imaging protocols for marginal savings in scan time, since we had shown that TBH used a limited number of standard examinations that had been consistently refined and optimised by both the vendor and international users over more than 30 years of clinical application.

From September 2012, MRI scanning hours were extended by nine hours per week (Tuesday - Thursday, 16h00 19h00). This intervention stabilised the waiting time but did not reduce it (Figure 1). Unforeseen barriers to successful utilisation of the additional scanning hours were transport problems amongst patients in getting to and from $\mathrm{TBH}$ in the early evening, and patient concerns for personal safety when travelling home.

From February 2013, TBH hospital management sanctioned a further 13 scanning hours per week, from $08 \mathrm{~h} 00-16 \mathrm{~h} 00$ on Saturdays and $08 \mathrm{~h} 00-13 \mathrm{~h} 00$ on Sundays. This resulted in an immediate and striking decrease in waiting time, from 125 working days in January 2013 to 59 days in May 2013 and 31 days in August 2013 (Figure 1).

The additional scanning hours were implemented at an estimated annual operating cost of R371 000 (about R7500/

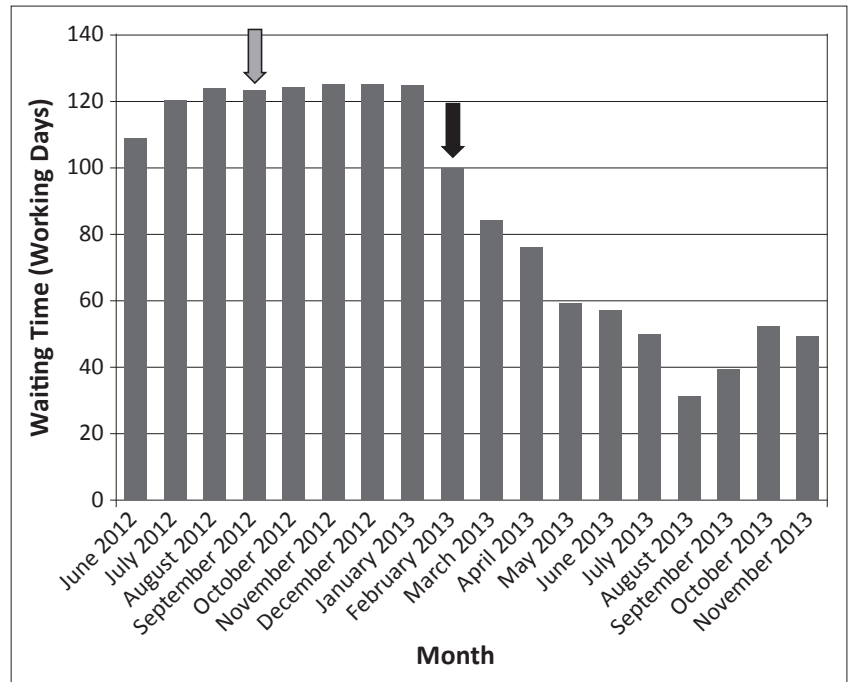

FIGURE 1: Elective MRI waiting time in working days. The grey arrow indicates when longer weekday hours were introduced. The solid black arrow indicates when weekend scanning was introduced.

weekend) for additional radiographic and nursing services. This represents approximately $2.5 \%$ of the current capital outlay for an MRI machine and approximates the 'cost-to-company' of one fulltime entry-level public-sector radiographer.

\section{Conclusion}

Some important considerations relating to the provision of capital-intensive imaging services in a resourcelimited healthcare environment have been highlighted. These include the imperative to constantly evaluate the appropriateness of clinical utilisation of a scarce resource, the ongoing challenge of matching clinical need with system capacity, the importance of collaboration between hospital management and the radiology department in addressing service pressures, and the potential for minor, affordable service changes to yield major clinical benefits.

Our experience suggests that the artificial barrier separating 'normal hours' and 'after hours' imaging services should be annulled in a resource-constrained environment, and that capital-intensive equipment should be fully utilised, seven days a week. ${ }^{1}$ We have demonstrated the substantial service benefits resulting from a small additional investment in key personnel. We recommend that all capital-intensive equipment be commissioned with budgetary provision for the personnel required to run an optimal service seven days a week.

\section{Acknowledgements Competing interests}

The authors declare that they have no financial or personal relationships that might have inappropriately influenced them in writing this article.

\section{Authors' contributions}

F.J.v.S (Tygerberg Hospital and Stellenbosch University) was solely responsible for data collection and collation. F.J.v.S 
(Tygerberg Hospital and Stellenbosch University) and C.A. (Tygerberg Hospital and Stellenbosch University) evaluated the appropriateness of all clinical requests. F.J.v.S and R.D.P. prepared the manuscript. C.A and R.D.P supervised the research project.

\section{References}

1. Runge VM. Current technological advances in magnetic resonance with critical impact for clinical diagnosis and therapy. Invest Radiol. 2013;48(12):869-877. http://dx.doi.org/10.1097/01.rli.0000434380.71793.d3

2. Hayempour BJ, Cohen S, Newberg A. Brain disorders: Evaluation by radiological techniques and nuclear medicine of the primitive major neuropsychiatric
disorders. J Alzheimers Dis Parkinsonism. 2013;3(2). http://dx.doi. disorders. J Alzheimers Dis
org/10.4172/2161-0460.1000117

2. Cheong JL, Coleman L, Hunt RW, et al. Infant cooling evaluation collaboration. Prognostic utility of magnetic resonance imaging in neonatal hypoxic-ischemic encephalopathy: Substudy of a randomized trial. Arch PediatrAdolesc Med. 2012;166(7):634-640. http://dx.doi.org/10.1001/archpediatrics.2012.284

4. Tourbah A. Contribution of imaging to the diagnosis of optic neuropathies. Rev Neurol (Paris). 2012;168(10):702-705. http://dx.doi.org/10.1016/j. neurol.2012.07.012

5. Conaghan PG, Ostergaard M, D'Agostino MA, et al. Proceedings from the 5th Annual International Society for Musculoskeletal Imaging in Rheumatology Annual Conference. Semin Arthritis Rheum. 2013;42(4):433-446. http://dx.doi. org/10.1016/j.semarthrit.2012.10.003

6. Moschetti K, Muzzarelli S, Pinget C, et al. Cost evaluation of cardiovascula magnetic resonance versus coronary angiography for the diagnostic work-up of coronary artery disease: Application of the European American College of Radiology Practice Guidelines and Technical Standards. Magnetic Resonance Materials in Physics, Biology and Medicine. 2013;26(1):S1-S150.

7. Frydrychowicz A, Lubner MG, Brown JJ, et al. Hepatobiliary MR imaging with gadolinium-based contrast agents. J Magn Reson Imaging. 2012;35(3):492-511. http://dx.doi.org/10.1002/jmri.22833

8. Trompoukis P, Papantoniou N, Chlapoutaki C, Mesogitis S, Antsaklis AJ. Fetal MRI Is it really helpful? Matern Fetal Neonatal Med. 2012;25(11):2363-2368. http:// dx.doi.org/10.3109/14767058.2012.69616

9. Lee $\mathrm{CH}$, Weinreb JC. The use of magnetic resonance imaging in breast cance screening. J Am Coll Radiol. 2004;1(3):176-182. http://dx.doi.org/10.1016/j. jacr.2003.12.008
10. Martin DR, Kalb B, Sauer CG, Alazraki A, Goldschmid S. Magnetic resonance enterography in Crohn's disease: Techniques, interpretation, and utilization for clinical management. Diagn Interv Radiol. 2012;18(4):374-386. http://dx.doi. org/10.4261/1305-3825.DIR.4893-11.2

11. Ip IK, Schneider L, Seltzer $S$, et al. Impact of provider-led, technology-enabled radiology management program on imaging. Am J Med. 2013;126(8):687-692. http://dx.doi.org/10.1016/j.amjmed.2012.11.034

12. Robinson JD, Hippe DS, Hiatt MD. The effect of a no-denial policy on imaging utilization. J Am Coll Radiol. 2013;10(7):501-506. http://dx.doi.org/10.1016/j. jacr.2013.01.022

13. Hendee WR. Addressing overutilization in medical imaging. Radiology 2010;257(1):240-245. http://dx.doi.org/10.1148/radiol.10100063

14. Perez FA, Jarvik JG. Evidence-based imaging and effective utilization: Lessons in neuroradiology. Neuroimaging Clin N Am. 2012;22(3):467-476. http://dx.doi. org/10.1016/j.nic.2012.05.002

15. Gonzales JM. Imaging professionals' beliefs on overutilization of CT and MRI exams. Radiol Manage. 2011;33(6):41-46.

16. Census 2011 Statistical release P0301.4. Pretoria: Statistics South Africa. [cited 22 February 2012]. Available from: http://www.statssa.gov.za/Publications/P03014/ P030142011.pdf

17. Ondategui-Parra S, Bhagwat JG, Zou KH, et al. Practice management performance indicators in academic radiology departments. Radiology. 2004;233(3):716-722. http://dx.doi.org/10.1148/radiol.2333031147

18. Barter S, Drinkwater K, Remedios D. Clin Radiol. 2009;64(3):284-290. http:// dx.doi.org/10.1016/j.crad.2008.09.008

19. Nuti S, Vainieri M. Managing waiting times in diagnostic medical imaging. BMJ Open. 2012;2(6):e001255. http://dx.doi.org/10.1136/bmjopen-2012-001255

20. Tokur $\mathrm{S}$, Lederle $\mathrm{K}$, Terris $\mathrm{DD}$, et al. Process analysis to reduce MRI access time at a German university hospital. Int J Qual Health Care. 2012;24(1):95-99. http:// dx.doi.org/10.1093/intqhc/mzr077

21. MacDonald SL, Cowan IA, Floyd RA, Graham R. Measuring and managing radiologist workload: A method for quantifying radiologist activities and calculating the full-time equivalents required to operate a service. J Med Imaging Radiat Oncol. 2013;57(5):551-557. http://dx.doi.org/10.1111/1754-9485.12091

22. American College of Radiology. ACR quality and safety guidelines. Updated June 2012. [cited 30 June 2013]. Reston: American College of Radiology. Available from: http://www.acr.org/Quality-Safety/Appropriateness-Criteria

23. Rosen MP, Oake N, Forster AJ, Goelman A, Levy F. The effect of imaging capacity on the imaging workup of patients with stroke: A preliminary case for a crosscountry comparison. J Am Coll Radiol. 2011;8(6):428-435. http://dx.doi. org/10.1016/j.jacr.2011.02.012 